\title{
Tick-box admission forms improve the quality of documentation of surgical emergencies, but have limited impact on clinical behaviour
}

G L Laing, MB ChB, FCS (SA), Cert Trauma Surgery (SA); J L Bruce, FCS (SA); D L Clarke, FCS (SA), MMedSci, MBA, MPhil

Pietermaritzburg Metropolitan Trauma Service, KwaZulu-Natal, South Africa, and Department of General Surgery, Nelson Mandela School of Medicine, College of Health Sciences, University of KwaZulu-Natal, Durban, South Africa

Corresponding author: D L Clarke (damianclar@gmail.com)

Introduction. We used modern error theory to develop a tick-box admission form for emergency surgical patients. The tick boxes were designed to actively direct care down appropriate clinical algorithms by encouraging staff to make decisions based on recorded clinical data. Objective. To audit the effect of these tick-box forms on the quality of documentation and the resuscitation process.

Methods. We designed and implemented a standardised tick-box admission form, and audited its impact by comparing 100 emergency surgical admissions before the intervention with 100 thereafter. We assessed the quality of the documentation in both groups and analysed the effect of use of the tick-box admission form and the decision nodes on the clinical behaviour of the admitting clinicians.

Results. The introduction of standardised tick-box admission forms dramatically improved the quality of documentation of acute surgical admissions. However, the impact of the decision nodes on clinical behaviour was less obvious. We demonstrated a tendency to cognitive dissonance in that, even though clinicians recorded abnormal physiological data, they did not consistently interpret this information correctly.

Conclusions. Although the use of tick-box admission forms improves the quality of documentation, the impact on clinical behaviour is less certain. Quality improvement is a multifactorial endeavour, and without a pervasive culture of patient safety, tick-boxes alone may well be ineffective. 


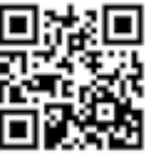

Human error is a significant problem in complex human organisations such as the aviation and nuclear power industries, and in modern trauma systems. However, the aviation and nuclear power industries have used insights provided by modern error theory to develop enviable safety records. To date, the healthcare system has not achieved a comparable record. ${ }^{[1-3]}$ The challenge to healthcare managers and clinicians is to use modern error theory to improve the quality of healthcare systems. Modern error theory provides insights into the evolution of error in healthcare systems by recognising that it is predominantly the system, rather than the individual, that fails. While individuals may make mistakes, it is the system that allows human error to affect patient care. A robust system directs care along certain desired pathways. If care does not follow the appropriate pathway, a robust system will autoregulate to redirect care down an appropriate pathway. If a system is not robust, it is possible for an individual to override it and violate protocols. Violations remain a significant cause of human error in healthcare systems.

A study from the University of Pittsburgh demonstrated a correlation between inadequate documentation of prehospital care and mortality. ${ }^{[4]}$ The authors reviewed all emergency medical service records for 2002 and 2003 in King County, Washington, USA. Multivariate analysis demonstrated that failure to record one or more physiological parameters at the scene of the injury predicted an increased risk of death. ${ }^{[4]}$ The authors concluded that inadequate record keeping reflected poor care. They rejected the hypothesis that the severity of the pathology treated by the prehospital staff meant that poor documentation merely reflected lack of time to make appropriate notes, and concluded that poor documentation is a proxy marker for poor care. We have previously audited the quality of documentation of trauma patients in our institutions and found it to be inadequate. ${ }^{[5,6]}$

\section{Objective}

We set out to address this deficit, and in light of the modern understanding of human error, sought to implement a standardised tick-box style admission form that would fulfil the dual role of improving the admission documentation of surgical patients and creating decision nodes to actively direct care down appropriate clinical algorithms (Appendix 1, available in the online version of this article).$^{[7,8]}$ By way of example, after making the admitting clinician document basic physiological data, a 'yes' or 'no' tick-box asking a clinical question such as 'is shock present?' or 'does the patient require active rewarming?' was included. This was intended to force a clinical decision and prompt an appropriate clinical response.

\section{Methods}

The study assessed the impact of the tick-box admission forms on patient safety by reviewing the quality of the data recorded and the impact of the forms on patient care. Before implementation of this intervention, all admission assessments were performed without any preprinted standardised rubric and it was our impression that the general quality of admission documentation was below an acceptable standard.

We audited 100 consecutive admissions before the introduction of this intervention. The issue of establishing an adequate benchmark for quality of documentation was discussed among senior departmental colleagues. We collectively came to a consensus that the following 29 criteria should be present in the assessment of any emergency surgical admission: admitting doctor's first and last name; patient's name and surname; a clear definition of the acute surgical pathology; time and date of clinical assessment; clarification of any significant previous medical history; clarification of any significant previous surgical history; clarification of any known allergies; clarification of any significant social history; pulse rate; blood pressure; respiratory rate; saturation of oxygen in haemoglobin $\left(\mathrm{PaO}_{2}\right)$; core body temperature; findings on examination of the central nervous system; findings on examination of the cardiovascular system and lungs; findings on abdominal examination; use of adjuncts during resuscitation; the type(s) of resuscitation fluids utilised; the volume of resuscitation fluids utilised; urine output volumes following resuscitation; requirement for antimicrobials; requirement for analgesia; laboratory investigations utilised; interpretation of laboratory investigation results; imaging investigations utilised; interpretation of imaging investigation results; communication with senior surgical staff; definitive clinical assessment; and definitive management plan.

The tick-box clerking form was designed by the authors. It was presented to all members of the surgical department using Microsoft PowerPoint with digital projection, together with hard copies of the form. The presentation involved a lecture on error theory and the importance of standardisation of accurate documentation (for the purposes of quality improvement), followed by a thorough orientation in the use of the form. This document was then implemented as departmental policy for the admission of all surgical patients. Medical doctors were the only staff permitted to admit surgical patients, with the demand that the tick-box form be completed following initial patient examination and stabilisation. No other ancillary staff member was involved in the exercise of using the form.

All surgical patients admitted to the Department of General Surgery at Grey's Hospital, Pietermaritzburg, KwaZulu-Natal, South Africa, were included in the study. We categorised the admission process into the following discrete steps based on current approaches to the acute management of trauma and sepsis: resuscitation (airway, breathing, circulation, core temperature, and neurological deficit), response to resuscitation (urine output), drugs used (antibiotics and analgesia), and need for added special investigations. The ten decision nodes illustrated in Table 1 were incorporated into the clerking sheet.

The study assessed the impact of this tick-box admission form on both the quality of the admission documentation and the clinical behaviour of the admitting clinician.

One month after implementation of the system, 100 tick-box admission forms were audited and compared with the previous method of admission in respect of quality. The authors performed the audit. We assessed the impact of the decision nodes on clinical behaviour by classifying responses as either compliant (tick-box was selected) or not compliant (tick-box was not selected). Thereafter, we analysed whether the compliant nodes were accurately or inaccurately selected using the following classification:

- compliant + accurate (pathology present and appropriately recognised)

- compliant + inaccurate (pathology present without recognition or intervention).

\section{Results}

Use of the tick-box admission form resulted in a significant improvement in the quality of recorded data (unpaired Student's $t$-test; $p=0.0006$ ). Table 2 compares the quality of the data recorded before and after the intervention, and illustrates improved data entry for all parameters. How this affected clinical care is less 
Table 1. Decision nodes

\begin{tabular}{|c|c|c|}
\hline Process & Clinical data & Decision node \\
\hline Resuscitation & Airway & Is an emergency airway required? \\
\hline Resuscitation & $\begin{array}{l}\text { Arterial oxygen } \\
\text { saturation }\left(\mathrm{SaO}_{2}\right)\end{array}$ & Is supplemental oxygen required? \\
\hline Resuscitation & $\begin{array}{l}\text { Blood pressure and } \\
\text { pulse }\end{array}$ & Is shock present? \\
\hline Resuscitation & $\begin{array}{l}\text { Core body } \\
\text { temperature }\end{array}$ & Is active rewarming of patient required? \\
\hline $\begin{array}{l}\text { Response to } \\
\text { resuscitation }\end{array}$ & Urine output & Is urine output normal or low? \\
\hline Drugs & $\begin{array}{l}\text { Indication for } \\
\text { antimicrobials }\end{array}$ & Are antibiotics required? \\
\hline Drugs & Pain & Is analgesia required? \\
\hline Investigations & Arterial blood gas & $\begin{array}{l}\text { Is the arterial blood gas normal or } \\
\text { abnormal? }\end{array}$ \\
\hline Investigations & Full blood count & Is full blood count normal or abnormal? \\
\hline Investigations & Urea and electrolytes & $\begin{array}{l}\text { Are urea and electrolytes normal or } \\
\text { abnormal? }\end{array}$ \\
\hline
\end{tabular}

certain; Table 3 summarises the analysis of the decision nodes.

Compliance was good for status of the airway, the need for supplemental oxygen and the haemodynamic status of the patients. It was poor in terms of assessing adequacy of urine output, the need for antibiotics and analgesia, and the need for review of blood results. However, despite compliance with completion of decision nodes, the interpretation of basic clinical data was not consistently correct. Six patients in this cohort were shocked on presentation: in one case the data were not recorded, and in four cases the data were recorded but the doctor failed to recognise the pathological condition. Similarly, in three patients with a core body temperature $<35^{\circ} \mathrm{C}$, the clinician did not recognise that active rewarming was indicated. No patients who required antibiotics were administered the appropriate drug, and 14 who required analgesia were not given it, despite the decision node

Table 2. Quality of the data recorded before and after the intervention

\begin{tabular}{llll}
\hline Resuscitation process & Clinical data & A (pre-intervention, $\boldsymbol{N = 1 0 0 ) , ~} \boldsymbol{n}$ & B (post-intervention, $\boldsymbol{N}=\mathbf{1 0 0}$ ), $\boldsymbol{n}$ \\
\hline Resuscitation & Respiratory rate & 22 & 80 \\
Resuscitation & Oxygen saturation & 45 & 84 \\
Resuscitation & Temperature & 30 & 67 \\
Resuscitation & CNS examination & 56 & 85 \\
Resuscitation & Type of fluid & 16 & 84 \\
Resuscitation & Volume of fluid & 9 & 46 \\
End-point of resuscitation & Urine output & 5 & 19 \\
Drugs & Antibiotics & 17 & 69 \\
Drugs & Analgesia & 18 & 61 \\
Investigations & ABG & - & 31 \\
Investigations & Urea and electrolytes & - & 44 \\
Investigations & Full blood count & - & 44 \\
A $=$ documented clinical variables pre-intervention; B $=$ documented clinical variables post-intervention; CNS = central nervous system; ABG = arterial blood gas.
\end{tabular}

Table 3. Summary of analysis of the decision nodes

\begin{tabular}{|c|c|c|c|c|}
\hline Resuscitation process & Decision node & $\begin{array}{l}\text { A (compliant, } \\
\text { total), } N\end{array}$ & $\begin{array}{l}\text { B (compliant, } \\
\text { accurate), } n\end{array}$ & $\begin{array}{l}\text { C (compliant, } \\
\text { inaccurate), } n\end{array}$ \\
\hline Resuscitation & Emergency airway & 99 & 98 & 1 \\
\hline Resuscitation & Oxygen required & 85 & 84 & 1 \\
\hline Resuscitation & Shock present & 81 & 76 & 5 \\
\hline Resuscitation & Active rewarming required & 72 & 68 & 4 \\
\hline End-point of resuscitation & Interpretation of urine output & 19 & 14 & 5 \\
\hline Drugs & Antibiotics administered & 56 & 47 & 9 \\
\hline Drugs & Analgesics administered & 61 & 47 & 14 \\
\hline Investigations & $\mathrm{ABG}$ & 31 & 30 & 1 \\
\hline Investigations & Urea and electrolytes & 62 & 53 & 9 \\
\hline Investigations & Full blood count & 44 & 43 & 1 \\
\hline
\end{tabular}


that actively asked whether or not analgesia was indicated. Nodes relating to the quantification of urine output, the administration of antibiotics and analgesics and the interpretation of laboratory results were particularly poorly completed. Fig. 1 shows examples of this cognitive dissonance: the admitting clinicians have recorded low systolic blood pressures and low core body temperature, but have incorrectly selected the 'shock not present' and the 'no need for active rewarming' tick-boxes, respectively. Compliance with documentation of special investigation results was poor: in 19 cases, abnormal urea and electrolyte results were incorrectly interpreted, and in eight cases abnormal full blood count results were not recognised.

\section{Discussion}

Preprinted tick-box forms have been shown to improve communication between units and hospitals, and checklists have been shown to improve safety in the operating room. ${ }^{[7-10]}$ This research has been adopted from the aviation industry, where checklist use is routine and has been successful in promoting safety and reducing error. ${ }^{[9,10]}$ Checklists fulfil a number of functions. They force staff to record specific data, which then fosters interpretation of and reaction to data results. They also promote teamwork and co-operation. However, checklists need to be implemented within a broader culture of patient safety if they are to be effective. Our experience supports this contention, as while our tick-box admission forms improved documentation, they did not necessarily improve quality of care, our audit revealing persistent violations of safe practice.

Documentation pertaining to the resuscitation process was well recorded, with the exception of the record of core body temperature. The monitoring of urine output as a guide to resuscitative efforts was poorly captured, as was the need for appropriate drugs. This is a significant failing, as delayed initiation of antibiotics predicts increased morbidity from sepsis. The timeous review of blood results was particularly poorly performed; once again this was a significant omission, as delayed recognition of acute kidney injury translates into increased morbidity. In addition to these limitations in the data capture process, the interpretation of data was problematic.

This misinterpretation of physiological data may be a result of cognitive dissonance, which is the psychological discomfort a person experiences when attempting to reconcile conflicting views of reality simultaneously. ${ }^{[1,2,11]}$ A view of reality is referred to as cognition. The theory states that people are driven to eliminate a feeling of dissonance by eliminating an existing cognition. In other words, an individual may be biased towards a certain decision, even though the evidence favours an alternative decision. We have previously described the problem of cognitive dissonance in trauma care. ${ }^{[3]}$ This study demonstrates that clinicians can fail to interpret abnormal clinical data. The examples cited in Fig. 1 illustrate the phenomenon of cognitive dissonance.

The major limitation of our tick-box admission forms is that it is a paper-based system. It is possible for clinicians to override (omit) the decision nodes, as there is no mechanical lockout system that forces them to comply. A mechanical lockout system is a generic errorreduction strategy that prevents the next step in a process, unless certain preceding tasks have been completed. ${ }^{[1-3]}$ The most common example of such a system is an online purchase system. It is designed to prohibit completion if certain mandatory data are not entered. The

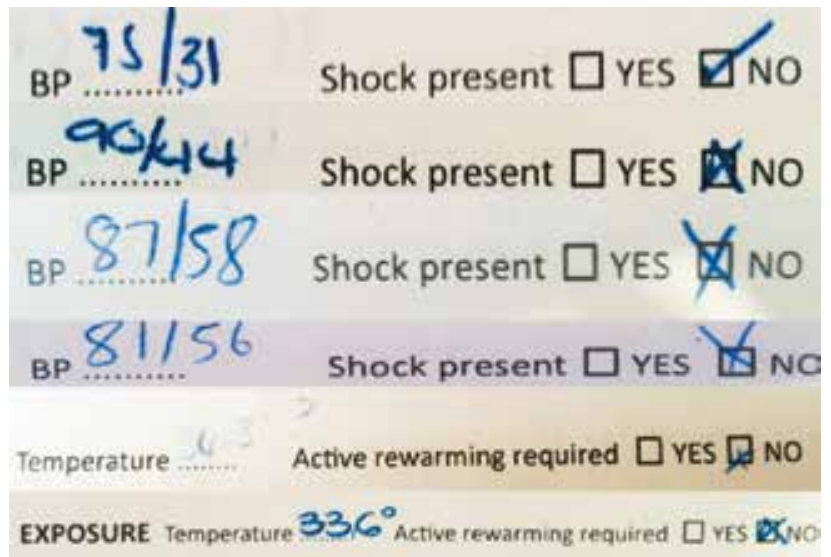

Fig. 1. Examples of cognitive dissonance.

purchaser is forced to either comply by entering mandatory data or abandon the process completely. We have shown that this pattern is difficult to achieve with a paper-based system, as it cannot overcome the problem of non-compliance and cognitive dissonance. Our research group's next intended step is to translate the current tick-box admission form into an electronic format. This could theoretically be designed with a mechanical lockout system and function as a clinical decision support system. Such systems include electronic prompts to promote compliance and direction of medical care down appropriate clinical pathways.

\section{Conclusion}

Our tick-box admission forms improved the quality of documentation, but revealed a significant incidence of violations of safe practice. Improving clinical care in our environment is a complex endeavour that requires a multifaceted approach with numerous interventions. A single isolated intervention is unlikely to be successful. Fostering a pervasive culture of patient safety is essential if tick-box admission forms are to be effective in the promotion thereof.

\section{References}

1. Reason J. Understanding adverse events: Human factors. Qual Health Care 1995;4(2):80-89. [http://dx.doi. org/10.1136/qshc.4.2.80]

2. Reason J. Human error: Models and management. BMJ 2000;320(7237):768-770. [http://dx.doi. org $/ 10.1136 / \mathrm{bmj} .320 .7237 .768]$

3. Clarke DL, Gouveia J, Thomson SR, Muckart DJ. Applying modern error theory to the problem of missed injuries in trauma. World J Surg 2008;32(6):1176-1182. [http://dx.doi.org/10.1007/s00268-008-9543-7]

Laudermilch DJ, Schiff MA, Nathens AB, Rosengart MR. Lack of emergency medical services documentation is associated with poor patient outcomes: A validation of audit filters for pre-hospital care. J Am Coll Surg 2010;210(2):220-227. [http://dx.doi.org/10.1016/j.jamcollsurg.2009.10.008]

5. Alexander T, Fuller G, Hargovan P, Clarke DL, Muckart DJ, Thomson SR. An audit of the quality of care of 5. Alexander T, Fuller G, Hargovan P, Clarke DL, Muckart D, Thomson SR. An audit of the quality of
traumatic brain injury at a busy regional hospital in South Africa. S Afr J Surg 2009;47(4):120-126.

traumatic brain injury at a busy regional hospital in South Africa. S Afr J Surg 2009;47(4):120-126.
6. Stewart WW, Farina Z, Clarke DL, Thomson SR. Variations in levels of care within a hospital provided to Stewart WW, Farina Z, Clarke DL, Thomson SR. Vari
acute trauma patients. S Afr J Surg 2011;49(4):194-198.

7. Goodyear HM, Lloyd BW. Can admission notes be improved by using preprinted assessment sheets? Qual Health Care 1995;4(3):190-193. [http://dx.doi.org/10.1136/qshc.4.3.190]

8. Fisher RB, Dearden CH. Improving the care of patients with major trauma in the accident and emergency department. BMJ 1990;300(6739):1560-1563. [http://dx.doi.org/10.1136/bmj.300.6739.1560]

9. Weiser TG, Haynes AB, Dziekan G, Berry WR, Lipsitz SR, Gawande AA; Safe Surgery Saves Lives Investigators and Study Group. Effect of a 19 item surgical safety checklist during urgent operations in aglobal patient population. Ann Surg 2010;251(5):976-980. [http://dx.doi.org/10.1097/SLA.0b013e3181d970e3]

10. Haynes AB, Weiser TG, Berry WR, et al.; Safe Surgery Saves Lives Study Group. A surgical safety checklist to reduce morbidity and mortality in a global population. $\mathrm{N}$ Engl J Med 2009;360(5):491-499. [http://dx.doi. org/10.1056/NEJMsa0810119]

11. Clark L. Decision-making during gambling: An integration of cognitive and psychobiological approaches. Philos Trans R Soc Lond B Biol Sci 2010;365(1538):319-330. [http://dx.doi.org/10.1098/rstb.2009.0147]

Accepted 3 April 2014 
Appendix 1

SURGERY ADMISSION SHEET

Admitting Doctor:

Patient Name

Surname

Age

Sex

IP Number

OP Number

Race

Time of Injury (T)

Date of Injury (T)

Time of Assessment

Date of Assessment

Mechanism of Injury (T)

Weapon Used (T)

\section{HISTORY}




\section{SURGERY ADMISSION SHEET}

\section{PRIMARY SURVEY}

\section{AIRWAY}

Hard collar $\square$ YES $\square$ NO Threatened airway $\square$ YES $\square$ NO Emergency airway required $\square$ YES $\square$ NO

\section{BREATHING}

Trachea central

Oxygen saturation.........

RR ........

Oxygen required $\square$ YES $\square$ NO

\section{CIRCULATION}

BP

Shock present $\square$ YES $\square$ NO

Vascular access

DISABILITY GCS ............

EXPOSURE Temperature.

Active rewarming required $\square$ YES $\square$ NO

SECONDARY SURVEY

Has ATLS Primary and Secondary survey been completed $\square$ YES $\square$ NO (T)

Have all systems been clinically examined and documented above ? $\square$ YES $\square$ NO 


\section{SURGERY ADMISSION SHEET}

\section{ADJUNCTS}

\begin{tabular}{|c|c|c|c|}
\hline$\square N G T$ & $\square$ Transurethral catheter & $\square$ supra-pubic catheter & $\square$ ECG \\
\hline Peripheral line & $\square$ Central line & drain & \\
\hline
\end{tabular}

Other

\section{RESUSCITATION}

$\square 0.9 \% \mathrm{NaCl} \quad \square \mathrm{MRL} \quad \square$ Colloid $\quad \square$ FDP $\quad \square$ Packed RBC's Other

Volume infused in Casualty Urine output on referral to OT/ward/ICU/ transfer $\mathrm{ml} / \mathrm{kg} /$ hour

$\square$ OLIGURIA $\square$ NORMAL URINE OUTPUT

Antibiotics administered $\square$ YES $\square$ NO

Analgesia administered $\square$ YES $\square$ NO

\section{INVESTIGATIONS}

Laboratory

$\square$ ABG $\square$ VBG $\square$ lactate $\square$ Glucose $\quad \square$ FBC $\square$ U+E $\square$ CMP $\square$ LfT $\square$ CK $\square$ serum Amylase $\square$ Cross match $\square$ Type and screen $\square$ Blood culture $\square$ INR $\square$ HIV

पUrine myoglobin $\quad \square$ Urine dipsticks $\quad \square$ Urine pregnancy test $\quad \square$ Urine MC+S

Other

Imaging

\begin{tabular}{|c|c|c|c|}
\hline $\begin{array}{l}\text { XR skull } \\
\text { FAST }\end{array}$ & $\begin{array}{l}\square \text { XR c-spine } \\
\square \text { Formal U/S }\end{array}$ & $\square \mathrm{CXR}$ & $\begin{array}{l}\square \text { AXR } \\
\square \text { CT scan }\end{array}$ \\
\hline
\end{tabular}

Other

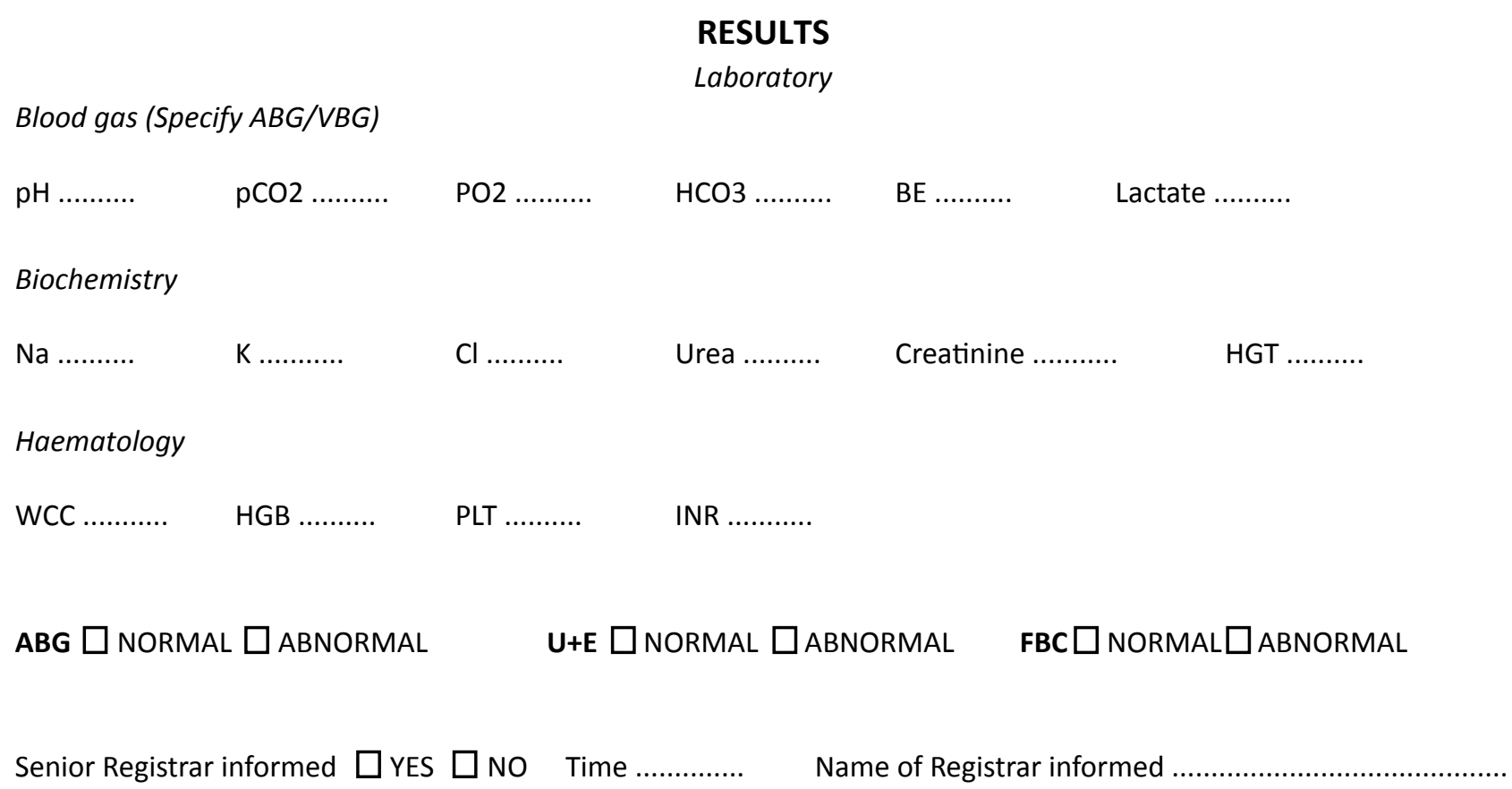


IMAGING POSITIVE FINDINGS

\section{ASSESSMENT}

\section{MANAGEMENT PLAN}

OPERATIVE INTERVENTION AND FINDINGS

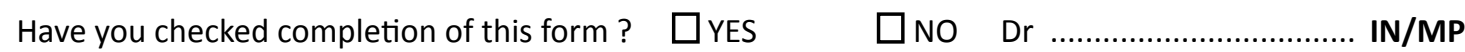

\section{(TO BE COMPLETED BY SENIOR REGISTRAR / MEDICAL OFFICER)}

$\begin{array}{lll}\text { Have you personally examined and assessed the patient ? } & \square \text { YES } \\ \text { Is your assessment and surgical plan documented? } & \square \text { YES } \\ \text { Have you chosen to communicate with consultant ? } & \square \text { YES } \\ \text { HNO } \\ \text { Does this patient require ICU or HCU referral ? } & \square \text { YES } \square \text { NO }\end{array}$

